\title{
Marketing through Social Media Influencers
}

\author{
Dr. Sherien Dajah \\ Lecturer / Management department \\ The World Islamic Sciences and Education University \\ Jordan
}

\begin{abstract}
Introduction
Marketing through social media influencers has become a popular phenomenon due to technological advancements and the need by organizations to take advantage of the new opportunities created by social media platforms such as Instagram. Social media influencers use their huge following in the various social media platforms to market products and reach an untapped market gap. An organization or individual can contract social media influencers to market goods through platforms such as YouTube, and Instagram (De Veirman 211). The influencers need to have a loyal following and a trusted figure that the organization can depend on to market its products. Social media influencers usually use techniques such as affiliate marketing, discount codes, giveaways, and the creation of useful content as ways of marketing goods.
\end{abstract}

\section{Affiliate Marketing and Discount Codes}

In affiliate marketing, an organization compensates a social media influencer who publishes leads or generate traffic to a company's goods. In this arrangement, the social media influencer acts as a third-party and is an affiliate to the organization, and the commission paid to him serves to incentivize him or her to promote the organization's goods. The influencers have to outsource customers for the organizations across their vast social media networks. An example of affiliate marketing is the partnership between Tim Ferriss and Audible. Tim Ferriss operates a TV show and is an investor and New York Times bestselling author (Saravanakumar \& SuganthaLakshmi 4450). During the Tim Ferriss Show, he speaks for a minute about the partnership and appeals to users to visit his custom URL where they can access a free eBook. Ferriss is, in this case, an influencer who gets paid by Audible to market free books through the custom URL.

Organizations can provide social media influencers with discount codes to offer to their followers to encourage the purchase of goods. The discounts offered by the influencers can either be a specific dollar amount or a given percentage of the good's cost and gives customers a reason to but the good. The discount codes are easy to track and embed in videos and graphics then share through platforms such as podcasts. The discount codes make the influencers work to be aggressive in searching customers for good through their online connections (Lou \& Shupei 70). The discount codes can be combined with tracking URLs to increase click-throughs for conversions and clients and efficiently track the brand. Through the tracking links, the social media influencer's discount is attached to a specific URL hence assisting him or her in monitoring both conversions fand traffics through the use of Google Analytics irrespective of the social media platform used by the influencer. The influencer can use tracking links in affiliate marketing when the company is paying out commission according to sales created by the influencer.

\section{Giveaways and Competition}

Social media influencers can be given a handful of products to give to their followers through giveaways, contests, and competition. The main purpose of giveaways and competition is to create avenues that will increase exposure to a brand's goods, thus driving customer engagement with the company. The influencers can unbox videos through their Instagram live video or YouTube channel to help shine a spotlight on an organization's products in front of the influencer's entire audience at very minimal operational cost. The influencers can be given exclusive products and many freebies to review on their social media platforms. The prizes given by the influencers should be lucrative in providing early access to the goods or getting people excited about the product (Brown \& Sam 34). As for competition, the influencers usually create more engaging guidelines that catch their audience's attention and keeps them engaged throughout the presentation.

\section{Creation of Useful Content}

Social media influencers can also market goods through the creation and distribution of relevant, consistent, and valuable content that attracts an explicitly defined audience. The main purpose of creating useful content is to retain important customers and drive profitability. In content marketing, the influencer provides useful customer information about the product, and it is useful in their present circumstances instead of pitching the products. 
The influencers use content marketing to improve conversions for an organization through connecting and educating potential customers about the benefits of a good. The influencers work to build trust and encourage conversion by giving clients important information when the need arises.

The creation of great content is less costly and an effective way of marketing as it results in new leads for the organization that has contracted the influencer. The content created by the influencer is essential for lead generation for organizations that depend on consistent traffic to boost sales and grow their brands (Mangold et al., 255). Leads are important for a business because they help an organization has a tight relation between the marketing and sales team as the two teams have to work together in growing the company. Social media influencers are useful in generating leads, thus marketing the organization on various platforms.

\section{References}

Brown, Danny, and Sam Fiorella. Influence marketing: How to create, manage and measure brand influencers in social media marketing. Que Publishing, 2013.

De Veirman, Marijke, Veroline Cauberghe, and Liselot Hudders. "Marketing through Instagram influencers: the impact of number of followers and product divergence on brand attitude." International Journal of Advertising 36.5 (2017): 798-828.

Lou, Chen, and Shupei Yuan. "Influencer marketing: how message value and credibility affect consumer trust of branded content on social media." Journal of Interactive Advertising 19.1 (2019): 58-73.

Mangold, W. Glynn, and David J. Faulds. "Social media: The new hybrid element of the promotion mix." Business horizons 52.4 (2017): 357-365.

Saravanakumar, M., and T. SuganthaLakshmi. "Social media marketing." Life Science Journal 9.4 (2012): 44444451. 